\title{
Risk assessment study of fire following an earthquake: a case study of petrochemical enterprises in China
}

\author{
J. Li ${ }^{1,2}$, Y. Wang ${ }^{1,2}$, H. Chen ${ }^{1,2}$, and L. Lin ${ }^{1,2}$ \\ ${ }^{1}$ Key Laboratory of Environmental Change and Natural Disaster of MOE, Beijing Normal University, No.19, \\ XinJieKouWai St., HaiDian District, 100875, Beijing, China \\ ${ }^{2}$ Academy of Disaster Reduction and Emergency Management, Beijing Normal University, No.19, XinJieKouWai St., \\ HaiDian District, 100875, Beijing, China
}

Correspondence to: Y. Wang (wy@bnu.edu.cn)

Received: 13 January 2013 - Published in Nat. Hazards Earth Syst. Sci. Discuss.: 29 April 2013

Revised: 6 November 2013 - Accepted: 11 November 2013 - Published: 16 April 2014

\begin{abstract}
After an earthquake, the fire risk of petrochemical enterprises is higher than that of other enterprises as it involves production processes with inflammable and explosive characteristics. Using Chinese petrochemical enterprises as the research object, this paper uses a literature review and case summaries to study, amongst others, the classification of petrochemical enterprises, the proportion of daily fires, and fire loss ratio. This paper builds a fire following an earthquake risk assessment model of petrochemical enterprises based on a previous earthquake fire hazard model, and the earthquake loss prediction assessment method, calculates the expected loss of the fire following an earthquake in various counties and draws a risk map. Moreover, this research identifies high-risk areas, concentrating on the Beijing-Tianjin-Tangshan region, and Shandong, Jiangsu, and Zhejiang provinces. Differences in enterprise type produce different levels and distribution of petrochemical enterprise earthquake fire risk. Furthermore, areas at high risk of post-earthquake fires and with low levels of seismic fortification require extra attention to ensure appropriate mechanisms are in place.
\end{abstract}

\section{Introduction}

Petrochemical enterprises produce products under complex process conditions and can be described as having the following characteristics: airtight environments, high temperatures, high pressure, deep cooling and pipelining in most cases, and involve raw materials and products that are inflammable, explosive, toxic, and corrosive. Further, such processes are prone to catch fire in daily production because of a number of factors including operation errors and equipment failure.

After a destructive earthquake strikes, fires are likely to occur in petrochemical enterprises with the leakage of inflammable and explosive substances, ignited by friction sparks or open flames as a result of earthquake damage to workshops, equipment, containers, and other structures. For example, during the Tangshan earthquake in China in 1976, a fire occurred in a synthetic fat factory in Tianjin, which totally destroyed the workshop after the sudden explosion of the synthetic tower resulting from a rise in temperature and pressure due to a power failure after workshop frames collapsed. A fire also broke out in a chemical plant in Hangu because of the spontaneous combustion of silicon dichloride following pipeline equipment damage with the collapse of buildings. Furthermore, a fire started in a factory in Hangu when a violent shake threw glycerin into a strong oxidant potassium permanganate and caused a chemical reaction (Business Community, 2008). During Japan's 2011 earthquake, numerous fires started in refineries in cities such as Sendai and Chiba, leading to a significant interruption of factory production (Sohu News, 2011a, b). Therefore, post-earthquake fires (secondary fires) constitute the greatest threat and harm to petrochemical enterprises (Hui and Jiang, 2002). In 1976, fires in petrochemical enterprises accounted for $24 \%$ of the total post-earthquake fires in Tianjin as a result of the Tangshan earthquake in China (Business Community, 2008). 
The total output value of the Chinese petrochemical industry makes up more than $12 \%$ of the gross industrial output value (China Petroleum and Chemical Industry Association, 2009). However, in terms of site selection, petrochemical enterprises' main concern is given to raw materials, product transport, and industrial basis, with little or no consideration for earthquakes. For example, a great many petrochemical enterprises, such as the Jianfeng enterprise, Youxin chemical plant, Hongda chemical plant, and Huafeng phosphorus chemical plant, are located along the Longmenshan Mountain fault belt where the Wenchuan earthquake occurred in 2008. Furthermore, the layout of most petrochemical enterprises significantly increases post-earthquake fire hazards.

From the perspective of the post-earthquake fire-causing mechanism of petrochemical enterprises, by summarizing the regular pattern of general fire occurrence in different types of enterprises, this paper can build a petrochemical enterprise post-earthquake fire risk assessment model based on the post-earthquake fire risk model put forward by Zhao Zhendong (Yu et al., 2003; Zhao et al., 2003) and earthquake loss prediction assessment methods. A macroanalysis will follow, with comments on the post-earthquake fire risk of Chinese petrochemical enterprises, and thus this paper can provide a scientific basis for regional economic development and industrial planning.

\section{Previous research}

Currently, the most common analysis model to determine the rate of post-earthquake fires is the empirical statistics regression model. Its aim is to find the expression between the postearthquake fire rate and post-earthquake fire factors using a regression analysis method based on statistics regarding historical earthquake damage.

Kobayashi (1984) performed a statistical regression analysis with historical earthquake secondary fire data and obtained expressions between the earthquake secondary fire incidence rate and house collapse rate. The expressions are regression models built in linear, logarithmic, and index forms with the number of post-earthquake fires per square meter of building as dependent variables and building collapse rates as independent variables. Scawthorn put forward a regression model (Scawthorn, 1986, 1996; Scawthorn et al., 1981), looking for a relationship between post-earthquake fire rates and earthquake intensity on the basis of collecting and analyzing data on 20th century post-earthquake fires in the United States. His results have been applied to the software package HAZUS developed by the Federal Emergency Management Agency (FEMA) to assess loss under the effect of multiple disasters, and to predict the number of postearthquake secondary fires in the United States.

In studying the fire after the Northridge earthquake in California, Trifunac and Todorovska $(1997,1998)$ found that fire ignition rate models correlated with site intensity, peak horizontal ground velocity, the number of red-tagged buildings, and breaks in water pipes. Based on the Monte Carlo simulation and physics-based fire-spread/evacuation simulation, Nishino et al. (2012) considered a number of factors (number and location of fire outbreaks, firefighting at the initial stages, weather, earthquake-related structural damage to buildings, initial evacuee locations, and the obstruction of roads) to simulate the burn-down risk and fire-fatality risk after an earthquake. Zhao (2010) built an integrated software system for the dynamic simulation of fires following an earthquake based on GIS; fire ignition, fire spread, and fire suppression were also considered in this system.

Tanaka (2012) studied the characteristics and problems of fires following the Great East Japan Earthquake in March 2011, and he classified post-earthquake fires into three types: conventional types of fires unrelated to tsunami waves, conflagrations in coastal areas inundated by the tsunami, and the peculiarities of tsunami-related fires. Fire characteristics are different from fire types. Fire ignition rates should be documented to determine the relative occurrence of gas, electrical, chemical and other types of fires (Trifunac and Todorovska, 1997).

The DOW Fire and Explosion Index method and the ICI MOND method, which was developed from the DOW Fire $\&$ Explosion Index by personnel at the Imperial Chemical Industries Mond division (Cai et al., 2009; Wang and Xu, 2009) have been adopted in petrochemical enterprise fire safety assessment studies for the quantitative study of the degree and loss of chemical fire risk on the basis of previous accident statistics, material potential energy, and the situation of current safety measures.

However, in view of there being relatively few studies on post-earthquake fires in petrochemical enterprises, $\mathrm{Xu}$ et al. (2002) presented methods to calculate the petrochemical enterprise post-earthquake fire probability via research on the relationships among the probability of petrochemical enterprise post-earthquake secondary fires, level of combustible hazard classification, and the level of equipment damage from earthquakes. Chen (2010) researched the risk of industrial enterprise secondary accidents in a natural disaster, based on energy transfer and fire dynamics energy theories, combined with a hazard and operability analysis (HAZOP) method.

\section{Mechanism and assessment models of petrochemical enterprise fire following an earthquake}

Figure 1 shows the post-earthquake fire-causing mechanism of petrochemical enterprises. The earthquake first damages workshops and equipment (this loss is called earthquake direct loss) in petrochemical enterprises, then triggers the leakage of flammable, explosive, toxic, and corrosive objects, which result in fire once they meet with an open flame or a spark caused by friction of some kind. Furthermore, 


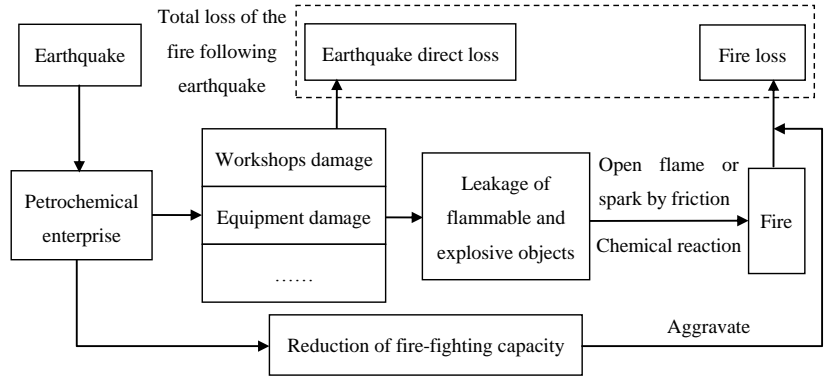

Fig. 1. Post-earthquake fire-causing mechanism of the petrochemical enterprises.

the earthquake can cause damage to fire-fighting facilities, pipelines, and roads, which reduces fire-fighting capacity. Thus, it accelerates the spread of fire and fire loss is greater (loss is referred to as fire loss). The sum of the above two losses is the total loss of the fire following an earthquake.

According to the above analysis, the calculation formula of post-earthquake fire total loss EFL is shown as Eq. (1), where EL denotes the direct loss of the earthquake and FL the fire loss.

$\mathrm{EFL}=\mathrm{EL}+\mathrm{FL}$.

It is necessary to classify the earthquake fire loss according to the petrochemical enterprise types that are susceptible to fire. The calculation formula of the direct earthquake loss EL in a certain petrochemical enterprise is shown in Eq. (2).

$\left(\mathrm{EL}_{R_{i}}\right)_{k}=\sum_{j=1}^{5} P\left(D_{j} \mid R_{i}\right) \cdot l_{D_{j}} \cdot W_{k}$.

In Eq. (2), $D_{j}$ refers to the damage level and $P\left(D_{j} \mid R_{i}\right)$ to the probability of the damage level $D_{j}$ with the seismic ground motion parameter $R_{i}$. Furthermore, $l_{D_{j}}$ denotes the earthquake loss ratio of the damage level $D_{j}, k$ the petrochemical enterprise type, and $W_{k}$ the total fixed assets of $k$ type petrochemical enterprises.

The calculation formula of a petrochemical enterprise's fire loss FL is shown in Eq. (3).

$$
\left(\mathrm{FL}_{R_{i}}\right)_{k}=\frac{1}{C} \cdot \sum_{j=1}^{5}[P(D j / R i) \cdot P(F k / D j)] \cdot l_{\mathrm{f}} \cdot W_{k}^{\prime} .
$$

In Eq. (3), $1 / C$ stands for safety measure failure coefficients, $P\left(F_{k} / D_{j}\right)$ for the post-earthquake fire occurrence probability of $k$-type petrochemical enterprises, $l_{\mathrm{f}}$ for the fire loss ratio, and $W_{k}^{\prime}$ for the value of $k$-type petrochemical enterprises before the fire occurs.

Where a fire occurs after an earthquake, $W_{k}^{\prime}$ stands for the surplus value after the earthquake damage, as shown in Eq. (4).

$W_{k}^{\prime}=W_{k}-\mathrm{EL}$.
In terms of the DOW Fire and Explosion Index assessment method, because process control, physical isolation, and fire prevention measures can reduce fire loss, security compensation coefficient $C$ is usually adopted to revise the index to ensure that the final loss assessment value better conforms to reality. An earthquake often reduces the local fire-fighting capacity, thus aggravating fire loss. In this case, the safety measure failure coefficient $1 / C$ can be used to revise fire loss when fire-fighting capacity has been reduced because of the earthquake.

Consulting the best safety measure compensation coefficient in the DOW Fire and Explosion Index assessment method, $C$ is established: $C=0.489$ and $1 / C=2.05$.

\section{Macro-risk assessment of China petrochemical enterprise fire following an earthquake}

\subsection{Earthquake hazard probability $P\left(D_{j} \mid R_{i}\right)$ and loss ratio $l_{D_{j}}$}

The 2000 seismic ground motion zonation map of China (China Earthquake Administration, 2001), as shown in Fig. 2, has seven levels: $<0.05 g, 0.05 g, 0.10 g, 0.15 g$, $0.20 \mathrm{~g}, 0.30 \mathrm{~g}$ and $\geq 0.40 \mathrm{~g}$, according to the seismic peak ground acceleration (PGA) in each region and the $10 \%$ of probability of exceedance in the class (medium hard) site over $50 \mathrm{yr}$.

Earthquake loss assessment in China classifies the damage levels of buildings into five levels: collapse, serious damage, medium damage, slight damage, and basically intact. Further, the assessment also provides (based on historical earthquake damage and experimental data) the probability $P\left(D_{j} \mid R_{i}\right)$ and loss ratio $l_{D_{j}}$ corresponding to different damage levels (earthquake loss prediction research team of China Earthquake Administration, 1990; Institute of Engineering Mechanics, 2005), as shown in Table 1.

As industrial factory buildings are the main assets of petrochemical enterprises, this paper takes the factory building loss ratio as the earthquake loss ratio $l_{D_{j}}$ of petrochemical enterprises. In Eq. (2), the $l_{D_{j}}$ is the loss ratio of petrochemical enterprises suffering from different degrees of seismic damage, and its range refers to the industrial factory building damage loss ratio in post-earthquake field works - Part 4: assessment of direct loss (GB/T 18208.4-2005) (Institute of Engineering Mechanics, 2005), as shown in Table 2.

\subsection{Petrochemical enterprise classification $k$ and asset value $W_{k}$}

A post-earthquake fire is subject to uncertainty due to numerous factors including the existence of combustibles, flammability of combustibles, and earthquake damage levels. Production equipment, technological processes, raw materials, and semi-finished and final products vary among petrochemical enterprises, which result in different fire probabilities. 


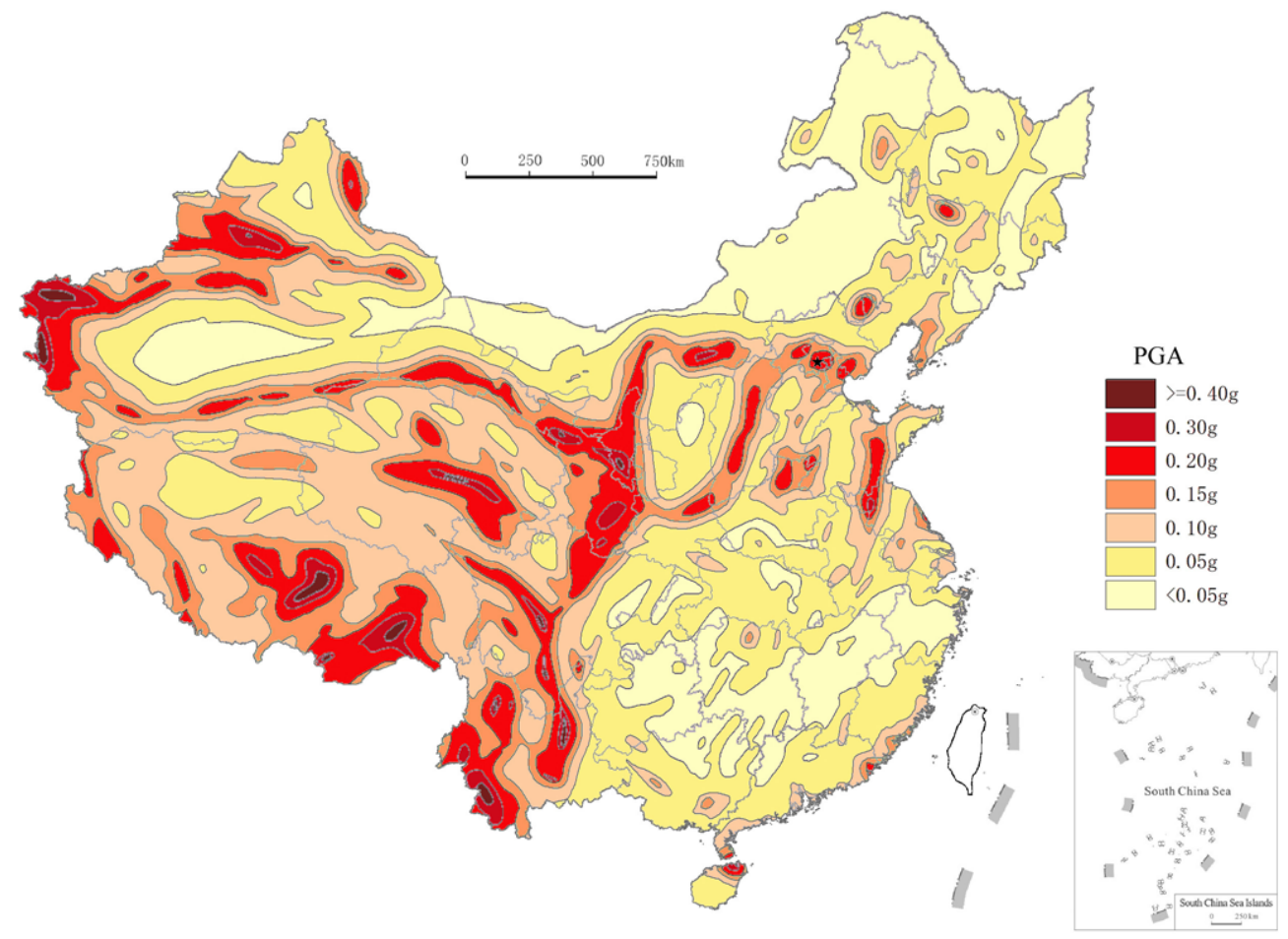

Fig. 2. Seismic ground motion parameter zonation map of China.

Table 1. The vulnerability matrix of industrial factory buildings.

\begin{tabular}{lrrrrr}
\hline & Collapse & Serious damage & Medium damage & Slight damage & Basically intact \\
\hline$P\left(D_{j} \mid R_{i}=0.05\right)$ & 0 & 0 & 0.07 & 0.2 & 0.73 \\
$P\left(D_{j} \mid R_{i}=0.1-0.15\right)$ & 0 & 0.03 & 0.12 & 0.28 & 0.57 \\
$P\left(D_{j} \mid R_{i}=0.20-0.3\right)$ & 0.02 & 0.15 & 0.31 & 0.28 & 0.24 \\
$P\left(D_{j} \mid R_{i}>=0.4\right)$ & 0.05 & 0.25 & 0.4 & 0.2 & 0.1 \\
\hline
\end{tabular}

Source: earthquake loss prediction research team of China Earthquake Administration (1990).

In accord with the Industrial Classification For National Economic Activities (GB/T 4754-2011) (National Bureau of Statistics of China, 2011), this paper divides petrochemical enterprises into four types: $\mathrm{PE}_{1}$, oil, natural gas drilling, petroleum processing, coking and nuclear fuel processing enterprises; $\mathrm{PE}_{2}$, chemical raw materials and chemical product manufacturing enterprises; $\mathrm{PE}_{3}$, chemical fiber manufacturing enterprises; $\mathrm{PE}_{4}$, rubber and plastic product manufacturing enterprises.

Considering the complexity of the value components of petrochemical enterprises and the availability of data, the fixed asset value $W_{k}$ is taken as the total values of petrochemical enterprises.

The fixed asset data $W_{k}$ for the four types of petrochemical enterprises were sourced from China's 2008 economic census data (Leading Group Office of the Second China Economic Census of the State Council, 2010), with the province as the basic statistical unit. In view of the lack of related county or city data regarding the fixed assets of petrochemical enterprise, this paper assigns province-level values for fixed assets to all cities and counties according to the industry output value ratio of every city or county to the whole province. Therefore, the distribution of the fixed assets of petrochemical enterprises for counties or cities is obtained in this paper. Figure 3 shows the distribution of the fixed assets per unit area of petrochemical enterprises.

\subsection{Fire hazard probability of different types of petrochemical enterprises}

The fire occurrence probability $P\left(F_{k} / D_{j}\right)$ of petrochemical enterprise depends on the probability $P\left(C_{j} \mid D_{j}\right)$ of leakage and diffusion of flammable materials in factories, the probability $P\left(S_{j} \mid D_{j}\right)$ of ignition, and the fire proportion $F_{k}$ of the petrochemical enterprise, as shown in Eq. (5) below.

$$
P(F k / D j)=P\left(C_{j} / D_{j}\right) \cdot P\left(S_{j} / D_{j}\right) \cdot F_{k} .
$$


Table 2. Industrial factory building damage loss ratio.

\begin{tabular}{lllll}
\hline Collapse & Serious damage & Medium damage & Slight damage & Basically intact \\
\hline $81-100 \%$ & $46-80 \%$ & $17-45 \%$ & $5-16 \%$ & $0-4 \%$ \\
\hline
\end{tabular}

Source: Post-earthquake field works - Part 4: assessment of direct loss (GB/T 18208.4-2005).

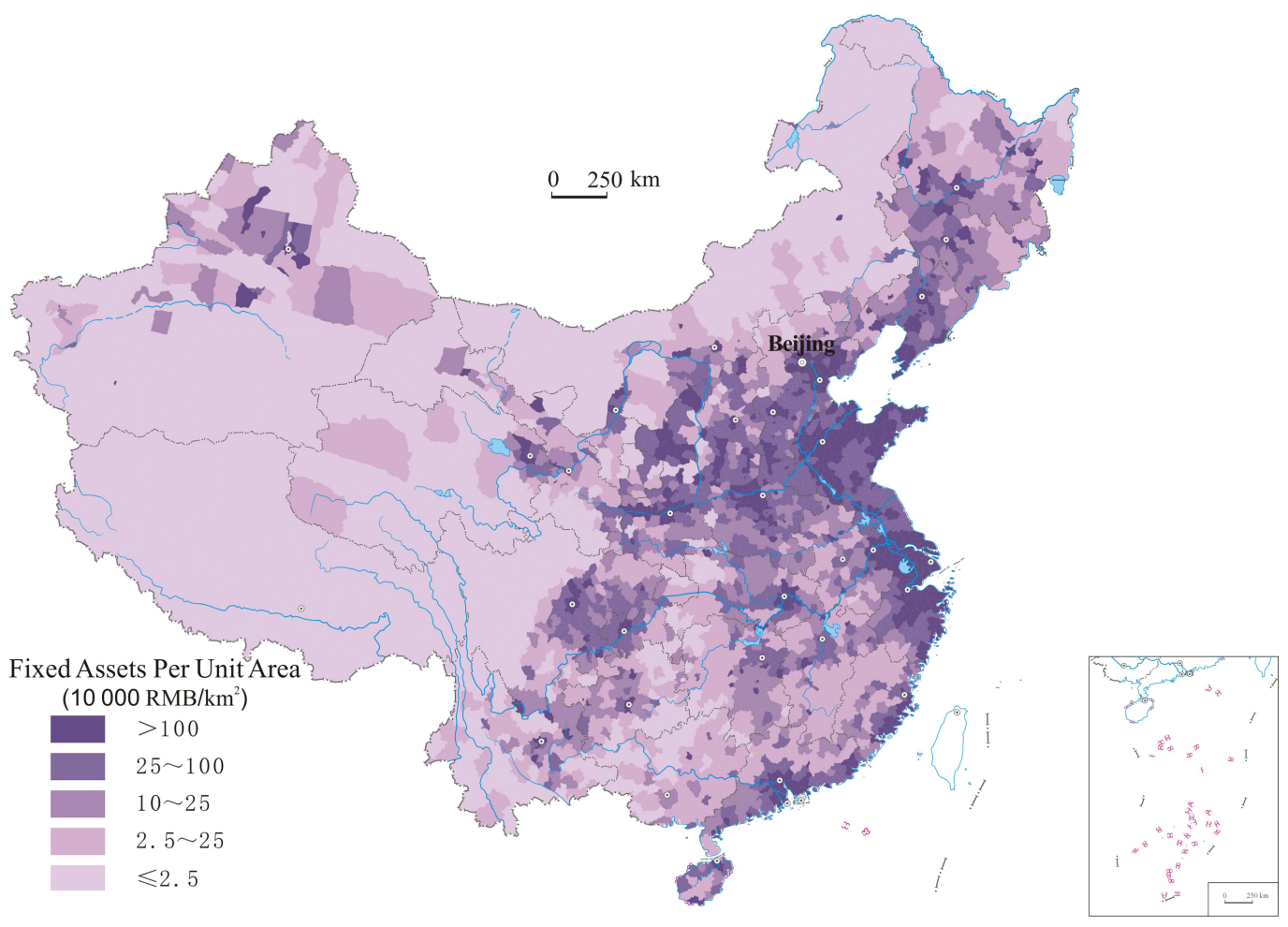

Fig. 3. Fixed assets per unit area of petrochemical enterprises.

Table 3 shows the data, the probability $P\left(C_{j} \mid D_{j}\right)$ of leakage and diffusion and the probability $P\left(S_{j} \mid D_{j}\right)$ of petrochemical enterprise fire occurrence at different levels of earthquake damage on the basis of historical data (Yu et al., 2003; Zhao et al., 2003).

$F_{k}$ is the daily fire occurrence proportion of petrochemical enterprises. Fire hazard probability varies among petrochemical enterprises because the chemical substances used in their production processes and the flammable materials in the factory buildings have different characteristics and are stored in various quantities (Sinopec Group, 2008; Ministry of Public Security of PRC, 2006). Therefore, this paper uses $F_{k}$ to adjust their fire hazard probability.

On account of the lack of official statistics regarding fires in petrochemical enterprises, this paper calculates $F_{k}$ by collecting data on 233 fires at petrochemical enterprises in China from January 2005 to July 2011; the data were sourced from China's most authoritative fire protection websites (China Fire Protection Website, 2005-2011; Huicong Fire Protection Website, 2005-2011). According to the China
Fire Services, the incidence of petrochemical enterprise fires was 579, 429, 532, 382, and 349 (Fire Department of the Ministry of Public Security of PRC, 2006-2010) for the year 2005, 2006, 2007, 2008, and 2009, respectively. The 233 records are in accord with the minimum sample size demand of the sample survey.

According to enterprise types, this paper divides the above fires into four categories $-\mathrm{PE}_{1}, \mathrm{PE}_{2}, \mathrm{PE}_{3}$, and $\mathrm{PE}_{4}$ - and calculates daily fire proportion for each category. The results are shown in Table 4; for $\mathrm{PE}_{2}$, the fire proportion of chemical raw materials and chemical product manufacturing enterprises is higher than for the other categories.

\subsection{Fire loss ratio $l_{\mathrm{f}}$ of petrochemical enterprises}

Considering the availability of data, this paper simplified the calculation of petrochemical enterprise fire loss ratio $l_{\mathrm{f}}$ by the average loss ratio, that is, the ratio of the average fire loss value to the average fixed asset value of petrochemical enterprises, as shown in Eq. (6) below. 
Table 3. Probability of leakage, diffusion, and fire occurrence of inflammable material.

\begin{tabular}{llllll}
\hline & Collapse & Serious damage & Medium damage & Slight damage & Basically intact \\
\hline Leakage, diffusion & 0.97 & 0.89 & 0.80 & 0.68 & 0.50 \\
$P\left(C_{j} \mid D_{j}\right)$ & $(0.94-1.00)$ & $(0.84-0.94)$ & $(0.75-0.84)$ & $(0.60-0.75)$ & $(0.40-0.60)$ \\
Fire occurrence & 0.97 & 0.89 & 0.80 & 0.68 & 0.50 \\
$P\left(S_{j} \mid D_{j}\right)$ & $(0.94-1.00)$ & $(0.84-0.94)$ & $(0.75-0.84)$ & $(0.60-0.75)$ & $(0.40-0.60)$ \\
\hline
\end{tabular}

Source: Zhao et al. (2003).

Table 4. Daily fire proportion for petrochemical enterprises.

\begin{tabular}{lrrrr}
\hline Enterprise type & $\mathrm{PE}_{1}$ & $\mathrm{PE}_{2}$ & $\mathrm{PE}_{3}$ & $\mathrm{PE}_{4}$ \\
\hline Daily fire proportion & 0.171 & 0.438 & 0.129 & 0.262 \\
\hline
\end{tabular}

Source: this study.

$l_{\mathrm{f}}=\frac{L_{\mathrm{f}}}{W}$

In this equation, $l_{\mathrm{f}}$ refers to the petrochemical enterprise daily fire loss ratio, $L_{\mathrm{f}}$ to the petrochemical enterprise daily fire average loss value, and $W$ to the average fixed asset value of a single petrochemical enterprise.

According to the average fixed asset value of petrochemical enterprises (Leading Group Office of the Second China Economic Census of the State Council, 2010) and petrochemical enterprise fire economic loss data (Fire Department of the Ministry of Public Security of PRC, 2006-2010) in 2008 , the petrochemical enterprise daily fire loss ratio $l_{\mathrm{f}}=0.001$.

\section{Fire following an earthquake risk of petrochemical enterprises for China's counties}

The seismic ground motion zonation map (Fig. 2) can help identify the level of seismic ground motions $R_{i}$ in each county and then obtain the $P\left(D_{j} \mid R_{i}\right)$ and $l_{\mathrm{f}}$. With the above loss ratio and fixed asset value, and Eqs. (1), (2), (3), and (4), the post-earthquake fire expected loss value of the four types of petrochemical enterprises in various counties can be calculated, as shown in Fig. 4a, b, c and d. Figure 4e shows a post-earthquake fire risk map of China's petrochemical enterprises, showing the loss value of the four types of petrochemical enterprises. Taking Heping District of Tianjin City for example, the PGA of this region is between $0.15 \mathrm{~g}$ to $0.20 \mathrm{~g}$. Table 5 shows the original data and results of this calculating process.

In each picture of Fig. 4, the colors (from dark to light) show the post-earthquake fire risk from high to low. Figure $4 \mathrm{e}$ shows that the high-risk post-earthquake areas are mainly distributed in central China, including the Beijing-TianjinTangshan region, Shandong, Jiangsu, Zhejiang provinces, and parts of Henan, Shanxi, Shaanxi, Sichuan, Yunnan, Xinjiang, and Guangdong provinces. Cause analysis shows, because of the post-earthquake fire risk chain, that high-risk areas of petrochemical enterprises are closely related to the distribution of seismic fault belts. For example, northern China, containing the north-south seismic belt, has historically experienced significant earthquakes and has a relatively high risk. In contrast, there is a close correlation between risk levels and output value of petrochemical enterprises. For example, the risk in Shandong and Jiangsu provinces is the highest because the petrochemical industry there is flourishing. In those two provinces, the total amount of fixed assets of large-scale (over RMB 5 million in annual sales) petrochemical enterprises accounted for over $10 \%$ of all fixed assets of petrochemical enterprises in China in 2008, and ranked first and second in China.

From the perspective of the specific risk distribution of the four types of petrochemical enterprises, as the fixed asset value of $\mathrm{PE}_{1}$ and $\mathrm{PE}_{2}$ enterprises are relatively high, so too are the corresponding risk levels, as shown in Fig. 4a and b. In contrast, the risk levels of $\mathrm{PE}_{3}$ and $\mathrm{PE}_{4}$ enterprises are relatively low, as shown in Fig. $4 \mathrm{c}$ and $\mathrm{d}$. The distribution of high-risk areas for all types of petrochemical enterprises is basically the same as the distribution in Fig. 4e.

The above expected loss is calculated in county unit, and if the expected loss in county is added up to the province unit, the result is shown in Table 6 , which is the top 10 expected loss of earthquake fire for provinces. The high loss areas are mainly concentrated in the Bohai Rim (Shandong, Tianjin, Liaoning, Hebei), the Yangtze River delta (Jiangsu) and Shanxi-Henan-Shaanxi region. But there are large differences between provinces in four types of enterprises, and the provinces should adopt different risk prevention measures according to their own development features of the petrochemical industry. For example, Shandong should pay attention to $\mathrm{PE}_{1}$ and $\mathrm{PE}_{2}$ earthquake-fire prevention; however, Jiangsu only needs to focus on $\mathrm{PE}_{2}$.

\section{Discussion}

The seismic ground motion zonation map (Fig. 2) is used to determine the seismic fortification of buildings in China. The seismic $\mathrm{PGA}=0.05 \mathrm{~g}$ is the minimum seismic fortification level, and PGA $<0.05 g$ is the non-seismic fortification 


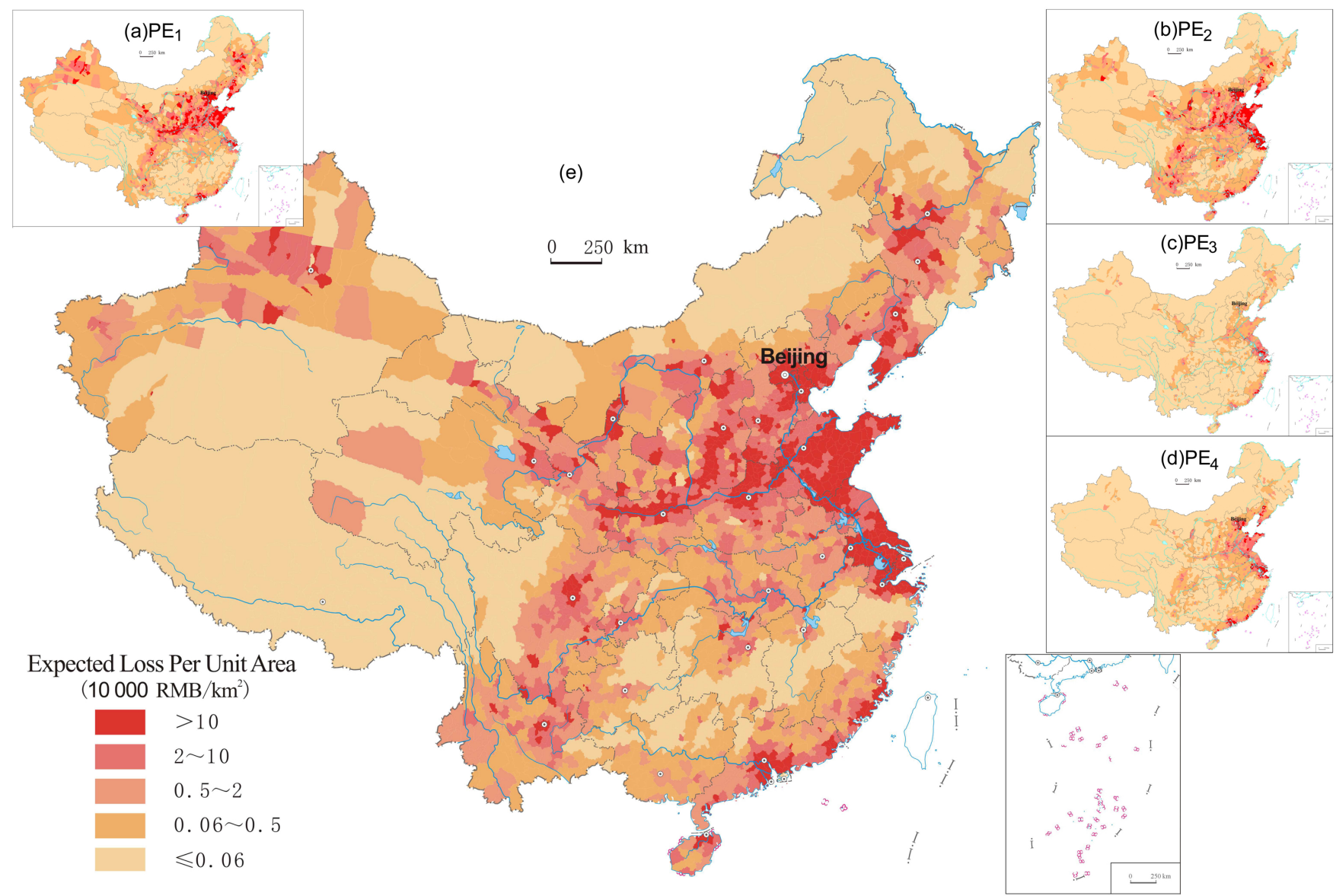

Fig. 4. Earthquake-fire risk map of petrochemical enterprises.

Table 5. Expected loss of earthquake-fire for the petrochemical enterprises in Heping District of Tianjin City.

\begin{tabular}{|c|c|c|c|c|c|}
\hline Petrochemical enterprises & $\mathrm{PE}_{1}$ & $\mathrm{PE}_{2}$ & $\mathrm{PE}_{3}$ & $\mathrm{PE}_{4}$ & Total \\
\hline Fixed assets in Tianjin City (RMB 10000$)^{*}$ & 7432100 & 2179400 & 30300 & 1390700 & 11032500 \\
\hline $\begin{array}{l}\text { Fixed assets in Heping District } \\
W_{k}(\text { RMB } 10000)\end{array}$ & 201806.96 & 59178.17 & 822.75 & 37762.27 & 299570.15 \\
\hline $\begin{array}{l}\text { Earthquake loss in Heping District } \\
\text { EL (RM } 10000)\end{array}$ & 49018.91 & 14374.38 & 199.85 & 9172.45 & 72765.59 \\
\hline $\begin{array}{l}\text { Residual values in Heping District } \\
W_{k}^{\prime}(\text { RMB } 10000)\end{array}$ & 152788.0 & 44803.79 & 622.90 & 28589.81 & 226804.5 \\
\hline $\begin{array}{l}\text { Fire loss in Heping District } \\
\text { FL (RMB } 10000)\end{array}$ & 28.86 & 21.68 & 0.089 & 8.27 & 58.90 \\
\hline $\begin{array}{l}\text { Total loss in Heping District } \\
\text { EFL (RMB } 10000)\end{array}$ & 49047.77 & 14396.06 & 199.9344 & 9180.729 & 72824.49 \\
\hline $\begin{array}{l}\text { Expected loss per unit area in Heping District } \\
\left(10000 \mathrm{RMB} \mathrm{km}^{-2}\right)\end{array}$ & 4619.57 & 1355.89 & 18.83 & 864.69 & 6858.98 \\
\hline
\end{tabular}

Source: this study; the item marked by an asterisk is collected from Leading Group Office of the Second China Economic Census of the State Council (2010). 


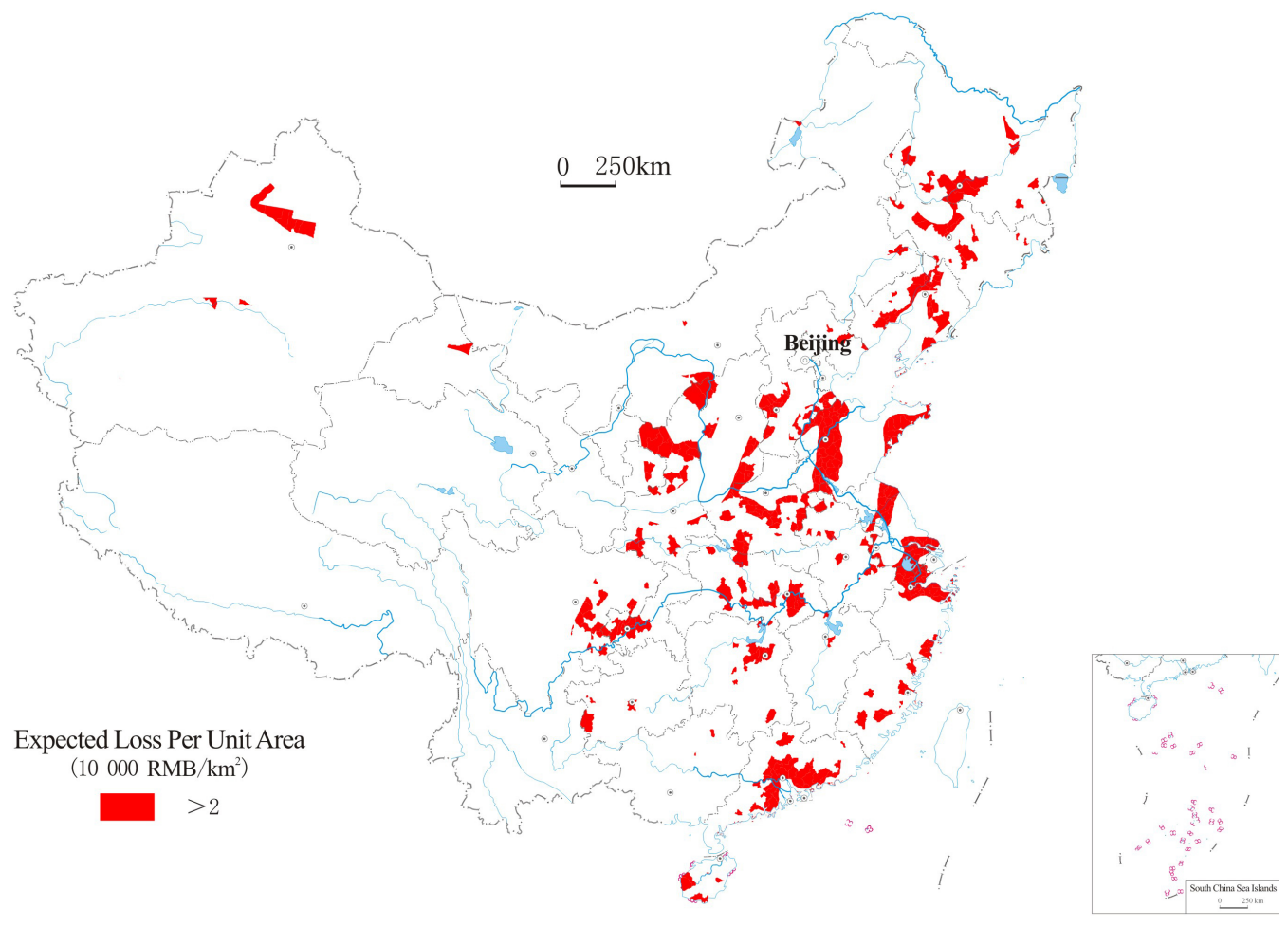

Fig. 5. Expected loss per unit area above RMB 20000 in seismic PGA $<0.05$ area.

Table 6. The top 10 expected loss of earthquake fire for provinces.

\begin{tabular}{lrrrrr}
\hline \multirow{2}{*}{ Province name } & \multicolumn{5}{c}{ Expected loss (unit: million Yuan RMB) } \\
\cline { 2 - 6 } & $\mathrm{PE}_{1}$ & $\mathrm{PE}_{2}$ & $\mathrm{PE}_{3}$ & $\mathrm{PE}_{4}$ & Total \\
\hline Shandong & 15132 & 15860 & 807 & 5287 & 37086 \\
Shaanxi & 27426 & 2741 & 6 & 244 & 30416 \\
Jiangsu & 2362 & 15931 & 3686 & 4840 & 26819 \\
Tianjin & 16503 & 4878 & 70 & 3091 & 24541 \\
Xinjiang & 20230 & 2941 & 251 & 209 & 23632 \\
Shanxi & 14715 & 7405 & 12 & 447 & 22580 \\
Liaoning & 11060 & 6881 & 426 & 2495 & 20863 \\
Hebei & 9309 & 5879 & 294 & 1930 & 17411 \\
Guangdong & 5036 & 6647 & 495 & 4982 & 17160 \\
Henan & 5137 & 6089 & 461 & 1203 & 12890 \\
\hline
\end{tabular}

Source: this study.

area. Using GIS software layer calculation functions, areas of PGA $=<0.05 g$ can be extracted from the seismic ground motion zonation map and areas with a local expected loss per unit above RMB 20000 (see Fig. 4e); the two areas can then be added together using GIS superposition to show where the two meet, as shown in Fig. 5.

The black areas in Fig. 5 show regions with low-level seismic fortification and a high risk of petrochemical enterprise post-earthquake fires; these areas are mainly distributed in the southern Shandong Peninsula, southern Jiangsu Province, and along the coast of the Hangzhou Bay and the Pearl River delta.

In accordance with the post-earthquake fire risk assessment results, the post-earthquake fire loss value per unit area is at a higher level in the above areas, where fire risk is often ignored because of the lower levels of seismic fortification. Accordingly, the level of fire protection construction in petrochemical enterprises is especially important in these areas; on the one hand, an appropriate emergency disaster plan should be formulated, and on the other, seismic standards should be taken into consideration when petrochemical enterprises undertake the construction of fire protection equipment and pipelines to ensure appropriate fire protection in an earthquake.

Because the occurrence of earthquake and the spread of following fire are concerned with many different factors that have complex relationships among each other, little attention is paid to the matter this paper focuses on, and therefore a complete research system is still on the way. Considering the capability of fire extinguishing, this study comprehends those fire hazard models and earthquake loss assessing methods and, furthermore, builds up the risk assessment model of fire following an earthquake of petrochemical enterprises. This paper applies previous research work and, what is more, makes meaningful academic exploration on the research ideas and performing methods of earthquake-fire risk 
assessing. Due to the lack of available data and the limitation of research methods, the model in this paper inevitably simplifies some parameters, and thus it has to focus on the discipline on macro-level, namely regional scale. In the coming days, deeper explorations are in great need on the factors and methods of earthquake-fire risk assessment.

\section{Conclusions}

The risk of fire is high for petrochemical enterprises, especially when buildings, chemical equipments, and fire-fighting capacity are damaged in an earthquake. This paper, based on the seismic ground motion zonation map, calculates the expected loss in a post-earthquake fire for four types of petrochemical enterprises in counties of China. The analysis focuses on the probability of flammable material leakage and diffusion, ignition source, and fire proportion of petrochemical enterprises.

Areas with a high risk of post-earthquake fires have a wide distribution in the Beijing-Tianjin-Tangshan region; Shandong, Jiangsu, and Zhejiang provinces; and in a number of counties in Henan, Shanxi, Shaanxi, Sichuan, Yunnan, Xinjiang and Guangdong. The risk of petrochemical enterprises requires extra attention and measures in some areas, especially where the level of seismic fortification is low.

In view of the available data, the calculation of some of the parameters used in this paper is conducted in a simplified way. Thus, further study is required to conduct a more precise risk assessment, including a more detailed classification based on petrochemical enterprise production processes, and the effect of varying earthquake intensities on chemical equipments, fire probability, and diffusion probability for all types of petrochemical enterprises.

Acknowledgements. This research was primarily supported by the National Key Technology R \& D Program of the 12th Five-Year Plan of China (no. 2012BAK10B03), the National Natural Science Funds (no. 41271544), and the Fundamental Research Funds for the Central Universities (2009SD-20).

Edited by: R. Lasaponara

Reviewed by: H. Ohtani and four anonymous referees

\section{References}

Business community: The reasons of the earthquake fire, available at: http://china.toocle.com/cbna/item/2008-09-19/3796526.html (last access: 26 July 2012), 2008.

Cai, F., Tan, Z., Meng, H., and Cai, R.: Chemical Process Safety Engineering, 2nd Edn., Science Press, Beijing, China, 2009.

Chen, X.: Study of assessment model on secondary accident risk triggered by natural disasters, M.S. thesis, Shenyang Aerospace University, Shenyang, China, 2010.
China Earthquake Administration: Seismic ground motion parameter zonation map of China (GB18306-2001), China Standards Press, Beijing, China, 2001.

China Fire Protection Website: available at: http://119.china.com. cn/, last access: 26 July 2012.

China Petroleum and Chemical Industry Association: Chinese chemical industry yearbook 2008, Second Volume, Chinese Chemical Industry Information Center, Beijing, China, 2009.

Earthquake loss prediction research team of China Earthquake Administration: Earthquake loss prediction research in China, Seismological Press, Beijing, China, 1990.

Fire Department of the Ministry of Public Security of PRC: China fire services (2005-2009), China Personnel Press, Beijing, China, 2006-2010.

Hui, Z. and Jiang, W.: Research on protection of earthquake fire for petrochemical enterprise, Petrochem. Safety Technol., 18, 3639, 2002.

Huicong Fire Protection Website: available at: http://www.fire. hc360.com/, last access: 26 July 2012.

Institute of Engineering Mechanics China Earthquake Administration: Post-Earthquake Field Works - Part 4: Assessment of Direct Loss (GB/T 18208.4-2005), Seismological Press, Beijing, China, 2005.

Kobayashi, M.: Urban post-earthquake fires in Japan, in: Proceedings of US-Japan Workshop on Urban Earthquake Hazards Reduction, Stanford Calif, 29 July-1 August, 121-133, 1984.

Leading Group Office of the Second China Economic Census of the State Council: China economic census yearbook 2008, Secondary Industry Volume, China Statistics Press, Beijing, China, 2010.

Ministry of Public Security of PRC: Code of design on building fire protection and prevention (GB 50016-2006), China Planning Press, Beijing, China, 2006.

National Bureau of Statistics of China: Industrial classification for national economic activities (GB/T 4754-2011), China Zhijian Publishing House, Beijing, China, 2011.

Nishino, T., Tanaka, T., and Hokugo, A.: An evaluation method for the urban post-earthquake fire risk considering multiple scenarios of fire spread and evacuation, Fire Safety J., 54, 167-180, 2012.

Scawthorn, C.: Fire following earthquake, in: First Safety ScienceProceedings of the First International Symposium, 971-979, 1986.

Scawthorn, C.: Fires following the Northridge and Kobe earthquake, Thirteenth Meeting of The UJNR Panel on Fire Research and Safety, New York, 13-20 March, 337-345, 1996.

Scawthorn, C., Yamada, Y., and Iemura, H.: A Model for urban post-earthquake fire hazard, Disasters, 5, 125-132, 1981.

Sinopec Group: Fire prevention code of petro chemical enterprise design (GB 50160-2008), China Planning Press, Beijing, China, 2008.

Sohu News: An explosion and fire at Chiba refinery in Japan, available at: http://news.sohu.com/20110311/n279776122.shtml (last access: 26 July 2012), 2011a.

Sohu News: An explosion and fire at an oil refinery in Sendai, Japan, available at: http://news.sohu.com/20110311/n279779460.shtml (last access: 26 July 2012), 2011 b.

Tanaka, T.: Characteristics and problems of fires following the Great East Japan earthquake in March 2011, Fire Safety J., 54, 197202, 2012. 
Trifunac, M. D. and Todorovska, M. I.: The Northridge, California, earthquake of 1994: density of pipe breaks and surface strains, Soil Dynam. Earthq. Eng., 16, 193-207, 1997.

Trifunac, M. D. and Todorovska, M. I.: The Northridge, California, earthquake of 1994: fire ignition by strong shaking, Soil Dynam. Earthq. Eng., 17, 165-175, 1998.

Wang, Q. and Xu, D.: Safety assessment operation, China Meteorological Press, Beijing, China, 2009.

Xu, J., Lin, J., Cao, H., Zhang, S., and Wang, X.: Risk evaluation and countermeasures of earthquake-induced fire in petrochemical enterprises, J. Nat. Disasters, 11, 134-140, 2002.
Yu, S., Zhao, Z., and Zhong, J.: Numerical simulation of secondary disasters of earthquake based on GIS, J. Nat. Disasters, 12, 100 $105,2003$.

Zhao, S.: GisFFE - an integrated software system for the dynamic simulation of fires following an earthquake based on GIS, Fire Safety J., 45, 83-97, 2010.

Zhao, Z., Zhong, J., and Yu, S.: Probability model for hazard analysis of post-earthquake fire occurrence and spread among buildings, Earthq. Eng. Eng. Vibrate, 23, 183-187, 2003. 